Photonirvachak

Journal of the Indian Society of Remote Sensing, Vol. 31, No. 4, 2003

\title{
Urban Growth Analysis Using Spatial and Temporal Data
}

\author{
H.S. SUDHIRA, T.V. RAMACHANDRA, KARTHIK S. RAJ AND K.S. JAGADISH* \\ Energy and Wetlands Research Group, Centre for Ecological Sciences \\ Indian Institute of Science, Bangalore - 560012 , India \\ *Department of Civil Engineering, Indian Institute of Science, Bangalore - 560 012, India
}

\begin{abstract}
Urban growth identification, quantification, knowledge of rate and the trends of growth would help in regional planning for better infrastructure provision in environmentally sound way. This requires analysis of spatial and temporal data, which help in quantifying the trends of growth on spatial scale. Emerging technologies such as Remote Sensing, Geographic Information System (GIS) along with Global Positioning System (GPS) help in this regard. Remote sensing aids in the collection of temporal data and GIS helps in spatial analysis. This paper focuses on the analysis of urban growth pattern in the form of either radial or linear sprawl along the Bangalore - Mysore highway. Various GIS base layers such as builtup areas along the highway, road network, village boundary etc. were generated using collateral data such as the Survey of India toposheet, etc. Further, this analysis was complemented with the computation of Shannon's entropy, which helped in identifying prevalent sprawl zone, rate of growth and in delineating potential sprawl locations. The computation Shannon's entropy helped in delineating regions with dispersed and compact growth. This study reveals that the Bangalore North and South taluks contributed mainly to the sprawl with $559 \%$ increase in built-up area over a period of 28 years and high degree of dispersion. The Mysore and Srirangapatna region showed $128 \%$ change in built-up area and a high potential for sprawl with slightly high dispersion. The degree of sprawl was found to be directly proportional to the distances from the cities.
\end{abstract}

\section{Introduction}

Understanding the driving forces of urbanisation and its spatial extent on a temporal scale would help in addressing the future needs of a region. This plays a key role in planning for infrastructure and becomes crucial in regional 
planning especially when resources are scarce. Unplanned urbanisation, which is often referred as sprawl, poses serious problems in infrastructure planning and implementation and can lead to unforeseen consequences. In this context, prior knowledge of patterns of human settlement and their trend would help the developmental agencies in planning for the basic amenities. To undertake such an assessment, spatial and statistical data for different time period are necessary. Temporal data acquired by remote sensing for a region along with the historical data, such as population growth patterns, that would help in finding out the patterns and trends of sprawl. Geographic Information System or GIS would help in integrating both spatial and statistical data and generate themes based on various growth trends.

The process of urbanisation is contributed by population growth and migration. Infrastructure initiatives result in the growth of villages into towns, towns into cities and cities into metros involving large-scale migration from rural to urban area. However, for ecologically feasible development, planning requires an understanding of the growth dynamics. Nevertheless, in most cases there is a lot of inadequacy to ascertain the nature of uncontrolled progression of urban sprawls. Sprawl is considered to be an unplanned outgrowth of urban centers along the periphery of cities, along highways, along the road connecting a city, etc. Due to lack of prior planning these outgrowths are devoid of basic amenities like water, electricity, sanitation, etc. Provision of certain infrastructure facilities like new roads and highways, fuel growth of sprawls, which ultimately result in inefficient and drastic change in land use patterns.

Usually sprawls occur on the urban fringe, at the edge of an urban area or along the highways in most parts of the globe. The need for understanding urban sprawl is already stressed (Sierra Club, 1998; The Regionalist, 1997) and attempted in the developed countries (Batty et al., 1999; Torrens and Alberti, 2000; Barnes et al.,
2001, Yeh and Li, 2001; Hurd et al., 2001; Epstein et al., 2002). Typically conditions in environmental systems with gross measures of urbanization are correlated with population density with built-up area (The Regionalist, 1997; Berry, 1990). Added to this, recently concluded 2001 national census shows that with the current trend, at least $33 \%$ of the Indian population would be in urban centers by 2016 . This substantiates the need to analyze and understand the urban sprawl phenomenon in the context of a developing country to address effective resource utilization and infrastructure allocation. Most investigations on sprawl, study either radial (across a city) or along the highways. In addition to these sprawls, there is a need to understand the sprawl that is taking place, when a city / town is connected by a road, which is most common in developing countries.

Normally, when the rural pockets are connected to a city by a road, at initial stages, development in the form of service centers such as shops, cafeteria, etc. can be seen on the roadside, which eventually becomes the hub of economic activity leading to sprawl. An enormous amount of upsurge could be observed along these roads. This type of upsurge caused by a road network between urban / semi-urban / rural centers is very much prevalent and persistent at most places in India. These regions are devoid of basic amenities, since regional planners were unable to visualize this type of growth. This growth is normally left out in all government surveys (census), as this cannot be grouped under either urban or rural. The investigation of patterns of this kind of growth is very crucial from regional planning point of view to provide basic amenities in these regions. In view of the Prime Minister of India's project, "Golden Quadrilateral of National Highways Development Project" for linking villages, towns and cities and building 4lane roads, this investigation is timely and significant. Prior visualization of the trends and patterns of growth enable the planning machineries to plan for appropriate basic infrastructure facilities (water, electricity, 
sanitation, etc.). The study of this kind reveals the type, extent and nature of sprawl taking place in a region and the drivers responsible for the growth. This would help developers and town planners to project growth patterns and facilitate appropriate infrastructure facilities. In this paper, an attempt is made to identify the sprawl pattern, quantify sprawl across roads in terms of Shannon's entropy (Yeh and Li, 2001), and estimate the rate of change in built-up area over a period with the help of spatial and statistical data of past three decades using GIS.

The physical expressions and patterns of sprawl on landscapes can be detected, mapped, and analyzed using remote sensing data and Geographical Information System (GIS) (Barnes et al., 2001). The patterns of sprawl could be described using a variety of metrics and through visual interpretation techniques. Characterization of urbanized landscapes over time and computation of spatial indices that measure dimensions such as contagion, the patchiness of landscapes, fractal dimension, and patch shape complexity are done statistically by Northeast Applications of Useable Technology In Land Use Planning for Urban Sprawl (Hurd et al., 2001; NAUTILUS, 2001).

In recent years understanding the dynamics of sprawl, quantifying them and subsequently predicting the same for a future period has attracted significant interest of researchers. Batty et al. (2001) have successfully analyzed this phenomenon using differential equations and developing a model to simulate sprawl using cellular automata for the Ann Arbor, Michigan region. Various issues concerned with quantifying urban sprawl phenomenon are addressed (Torrens and Alberti, 2000; Barnes et al., 2001) to arrive at a common platform for defining the process. Most of these studies quantify sprawl considering the impervious or the built-up areas as the key indicator of sprawl.

While describing the degree of disorganization of particles, the most often used term is 'entropy'. In spatial parlance, the entropy is linked to the dispersion of the spatial variable in a given region or boundary and is given by the Shannon's entropy. This index refiects the concentration of dispersion of spatial variable in a specified area, to measure and differentiate types of sprawl it would be useful in quantifying the sprawl (Yeh and Li, 2001). This measure is based on the notion that landscape entropy or disorganization increases with sprawl. The urban land uses are viewed as interrupted and fragmented previously homogenous rural landscapes, thereby increasing landscape disorganization. Similar approach was adopted to quantify urban sprawl in Udupi - Mangalore highway (Sudhira et al., 2003) and for Hyderabad City, India (Lata et al., 2001).

\section{Built-up Area as an Indicator of Urban Sprawl}

The percentage of an area covered by impervious surfaces such as asphalt and concrete is a straightforward measure of development and these surfaces can be easily detected and interpreted in remotely sensed data in developed countries (Barnes et al, 2001). This is based on the assumption that developed areas have greater proportions of impervious surfaces, i.e. the builtup areas as compared to the lesser-developed areas. In certain localities of developing countries, sprawl is also characterized by slums (region with poor housing and amenities), which can also be quantified using remotely sensed data.

Further, the population in the region also influences sprawl. The proportion of the total population in a region to the total built-up of the region is a measure of quantifying sprawl. Epstein et al. (2002) also employed a similar technique for mapping suburban sprawl and compared the result with rural and urban centers. Thus the sprawl is characterized by an increase in the builtup area along the urban and rural fringe and this attribute gives considerable information for understanding the behaviour of such phenomenon. Earlier studies carried out in 
different parts of the world highlight and conform that the built-up area could be used as fairly accurate parameter for urban sprawl analyses. The other parameter that is considered as an indicator of urban sprawl is the nighttime data captured with the help of radars or geo-stationary satellites (Sutton et al., 1997; Welch, 1980).

\section{Study Area}

This study was carried out in the Bangalore Mysore highway. Eight taluks straddle the Bangalore - Mysore highway as well as areas adjacent to these, which have been influenced by the highway. It includes Mysore taluk of Mysore district, Srirangapatna, Mandya and Maddur taluks of Mandya district, Channapatna, Ramanagaram, Bangalore South and Bangalore North taluks of Bangalore district. This is one of the well-linked regions of Karnataka state and covers an area of $4,152 \mathrm{~km}^{2}$ with about 1,013 settlements. This segment happens to be one of the prime urban corridors of the state. The cities like Mysore, Srirangapatna and Bangalore have been capitals of erstwhile kingdoms and so naturally development has its effect since historical time. However, expansion of Bangalore in recent times, as a major economic centre with development of industries and commercial establishments has given impetus to the growth. Early 90's boom in the software sector with consequent infrastructure initiatives, has contributed to hike in population, mainly due to migration from other parts of India to Karnataka. The radial sprawl due to Bangalore city's growth is seen curbing smaller villages on the periphery.

The objective of the study was to delineate the sprawl that is taking place along the highway between Bangalore and Mysore. During the exploratory survey, it was found that there was strong presence of sprawl within a buffer of $4 \mathrm{~km}$ around the highway and hence, it was decided for detailed investigations within a buffer of $4 \mathrm{~km}$ around the highway. The present investigation analyses the growth pattern within the buffer region across the roads connecting Bangalore with Ramanagaram, Ramanagaram with Channapatna, Channapatna with Maddur, Maddur with Mandya, Mandya with Srirangapatna and Srirangapatna with Mysore (Fig. 2).

\section{Data Collection}

The data collection involved collection of toposheets, village maps, satellite data and demographic details. The nature of these data and their source are shown in Table 1. The Survey of India toposheet of 1:50,000 scale was used for the current study, which has the following features:

- Drainage, water bodies, irrigation systems;

- Contours;

- Built-up area;

- Roads and rail network; and

- Administrative boundaries.

\section{Methodology to Measure Urban Sprawl}

The complexity of a dynamic phenomenon such as urban sprawl could be understood with the analyses of land use changes, sprawl pattern and computation of sprawl indicator index. As a prelude to this analysis, GIS base layers such as, road network and the administrative boundaries from the toposheets as shown in Table 1 were created. The highway passing between the two cities was digitized separately and a buffer region of $4 \mathrm{~km}$ around this was created. This buffer region is created to demarcate the study region around the road. Following this, land cover and land use analyses were done using remote sensing data.

The growth of urban sprawl over a period of three decades (1972-98) was determined by computing the area of all the settlements from toposheets of 1972 and comparing it with the area obtained from the classified satellite imagery for the built-up theme. The detailed methodology followed is depicted in the flow chart (Fig. 1). The toposheets (Table 1) in digital format were scanned and then geo-registered. The area under built-up (for 1972) was added to this attribute database after digitization of the toposheets for the built-up feature for the study area. 


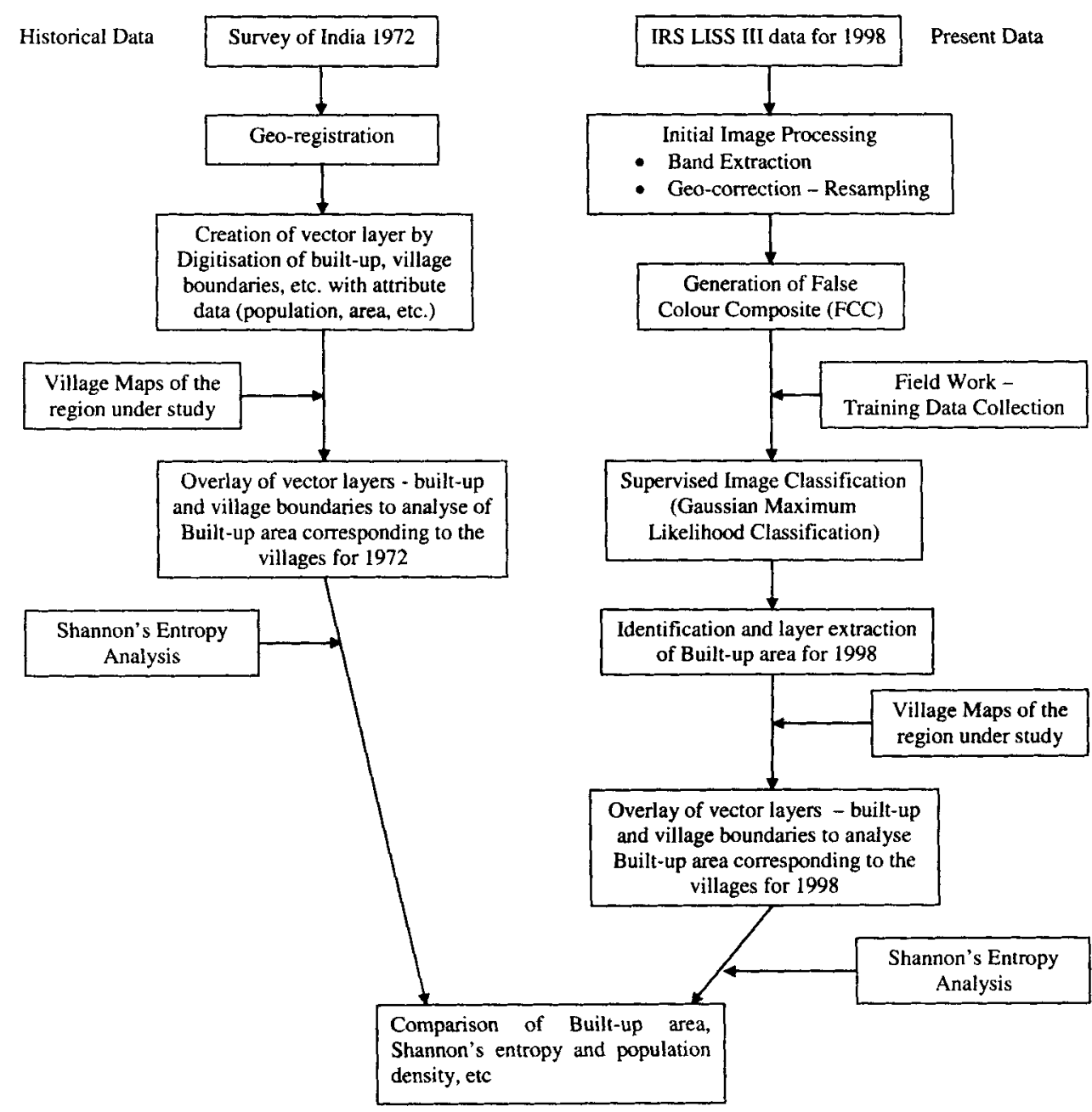

Fig. 1. Flow chart of methodology of analysis of Urban growth

Table 1: Primary and Secondary Data Details for the Study Area

\begin{tabular}{|l|l|}
\hline Segment : Mysore Bangalore & Source \\
\hline $\begin{array}{l}\text { Toposheets No. } 57 \mathrm{H} / 2,57 \mathrm{H} / 5,57 \mathrm{H} / 6, \\
57 \mathrm{H} / 9,57 \mathrm{D} / 11,57 \mathrm{D} / 14, \text { and } 57 \mathrm{D} / 15\end{array}$ & Survey of India, scale 1:50000 \\
\hline $\begin{array}{l}\text { Satellite Imagery - LISS III; Path: 100 Row: } \\
64 \text { \& Path: 99 Row: 65 }\end{array}$ & National Remote Sensing Agency (NRSA) \\
\hline $\begin{array}{l}\text { Demographic details from primary census } \\
\text { abstracts for 1971, 1981 \& 1991 }\end{array}$ & $\begin{array}{l}\text { Directorate of Census Operations, Census } \\
\text { of India }\end{array}$ \\
\hline $\begin{array}{l}\text { Village maps for Taluks, viz. Bangalore South, } \\
\text { Bangalore North, Ramanagaram, Channapatna, } \\
\text { Maddur, Mandya, Srirangapatna, Mysore }\end{array}$ & $\begin{array}{l}\text { Directorate of Survey Settlement and Land Records, } \\
\text { Government of Karnataka }\end{array}$ \\
\hline
\end{tabular}




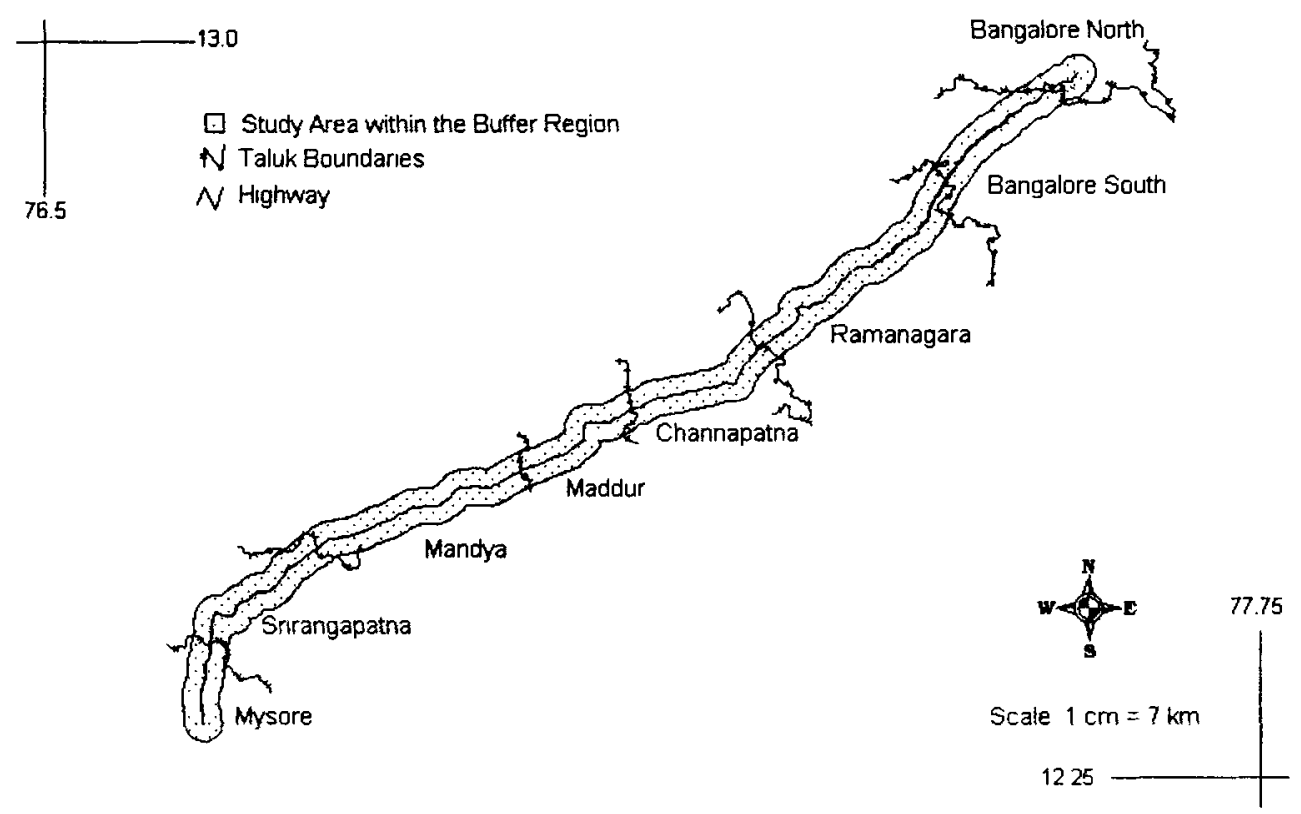

Fig. 2. Location of Study Area

Satellite images - IRS - LISS III data scenes covering Path 99 - Row 65 and Path 100 - Row 64 were procured from National Remote Sensing Agency (NRSA), Hyderabad for the year 1998. The image obtained from NRSA was georegistered with respect to the Survey of India toposheets.

The standard processes for the analyses of LISS III data such as band extraction, restoration, classification, and enhancement were carried out. Band extraction was done initially through a programme written in $\mathrm{C}++$ and subsequently IDRISI 32 was used for image analyses. The remote sensing data was then classified and analysed.

Area under built-up theme after classification was extracted from classified images, which gave the urban area of 1998. Further, by overlaying the layer of built-up area with the layer of village boundary, the built-up area under villages for the region was computed.

\section{Shannon's Entropy}

The Shannon's entropy (Yeh and Li, 2001) was computed to detect and quantify the urban sprawl phenomenon. The Shannon's entropy, $H_{n}$ is given by,

$$
H_{n}=-\Sigma P_{i} \log _{e}\left(P_{i}\right)
$$

where;

$P_{i}=$ Proportion of the variable in the $i^{\text {th }}$ zone (i.e. proportion of built up area in each village)

$\mathrm{n}=$ Total number of zones (i.e. number of villages in the region)

The value of entropy ranges from 0 to $\log n$. Value of 0 indicates that the distribution is very compact, while values closer to $\log \mathrm{n}$ reveal that the distribution is very dispersed. Higher values of entropy indicate the occurrence of sprawl (refer annexure for computation details). 


\section{Results and Discussion}

The built-up area for 1972 was extracted from the toposheets and is shown in Fig. 3. Then village-wise built-up area was computed by overlaying the layer with village boundaries (taluk map with village boundaries) and added to the attribute database for further analyses.

Geo-registered LISS III data obtained from NRSA (bands 2, 3 and 4 corresponding to G, R, NIR) were geo-corrected using resampling techniques. This is done with the help of known points on the Survey of India toposheets or / and ground control points (GCPs) using GPS. The RMS error in geo-correction was 0.0000674: The data acquired in bands -Green, Red and Near Infrared were used to generate a False Colour Composite (FCC). To create the composite image from three input bands, each of the three bands is stretched to 6 levels $\left(6^{*} 6 * 6=216\right)$. The composite image consists of color indices where each index $=$ Green $+(\operatorname{Red} * 6)+($ Near Infrared $*$ 36) assuming a range from $0-5$ on each of the three bands. For example, a pixel values of $3,5,1$ respectively for the three bands, Green, Red and Near Infrared would have an index of $3+(5 * 6)+$ $(1 * 36)=69$. The 256 Color Composite palette colors correspond to the mix of Green, Red and Near Infrared in the stretched images. In the composite image, heterogeneous patches were identified and the corresponding attribute data was collected using GPS (Global Positioning System). The training data collected accounted initially for 16 land use sub classes. Corresponding to the training data, signature files with attribute information were created. For the image classification supervised classification by the Maximum Likelihood Classifier (MLC) or Gaussian classifier was employed and image was classified for 16 land use types. Then the image was reclassified to four broader categories as vegetation, water bodies, open land, and built-up. The built-up theme identified from the image is shown in Fig. 4. Post classification field verification indicated the classification accuracy of $80 \%$ (i.e. 80 out of 100 polygons were found to be accurately classified as built-up).

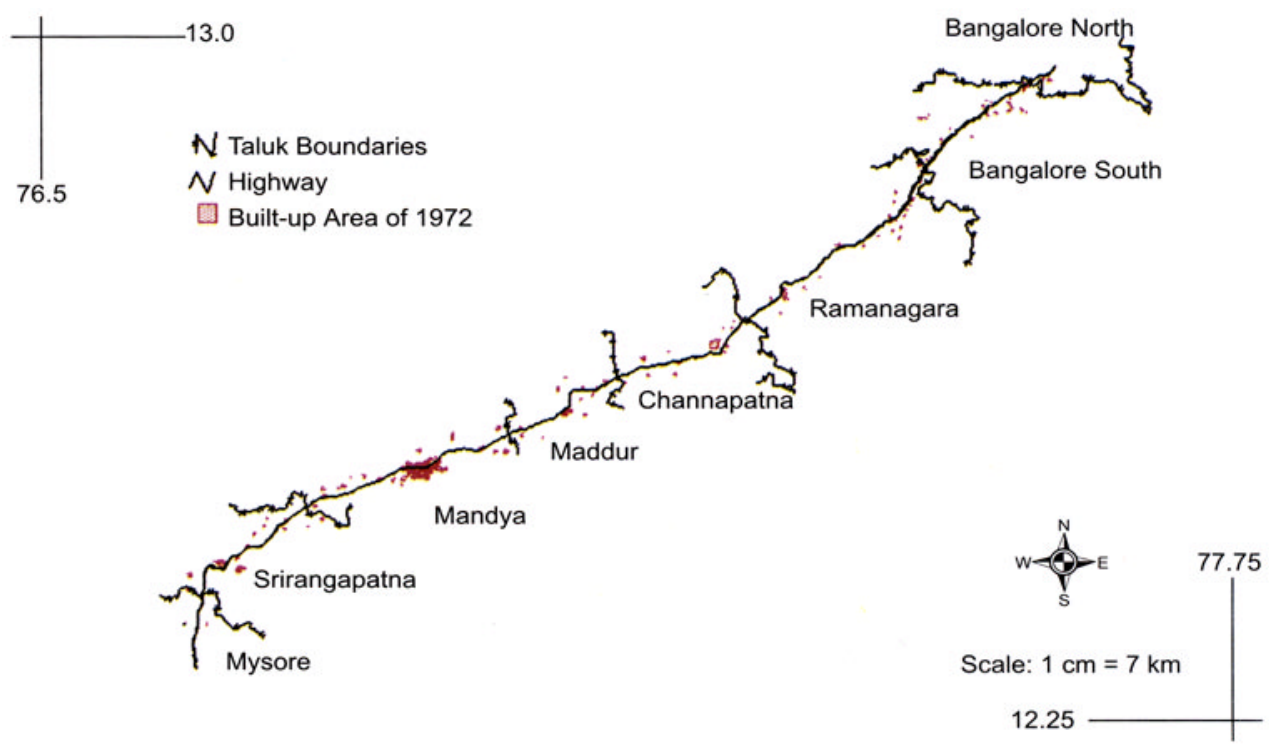

Fig. 3. Built-up Area in the Bangalore - Mysore Segment in 1972 


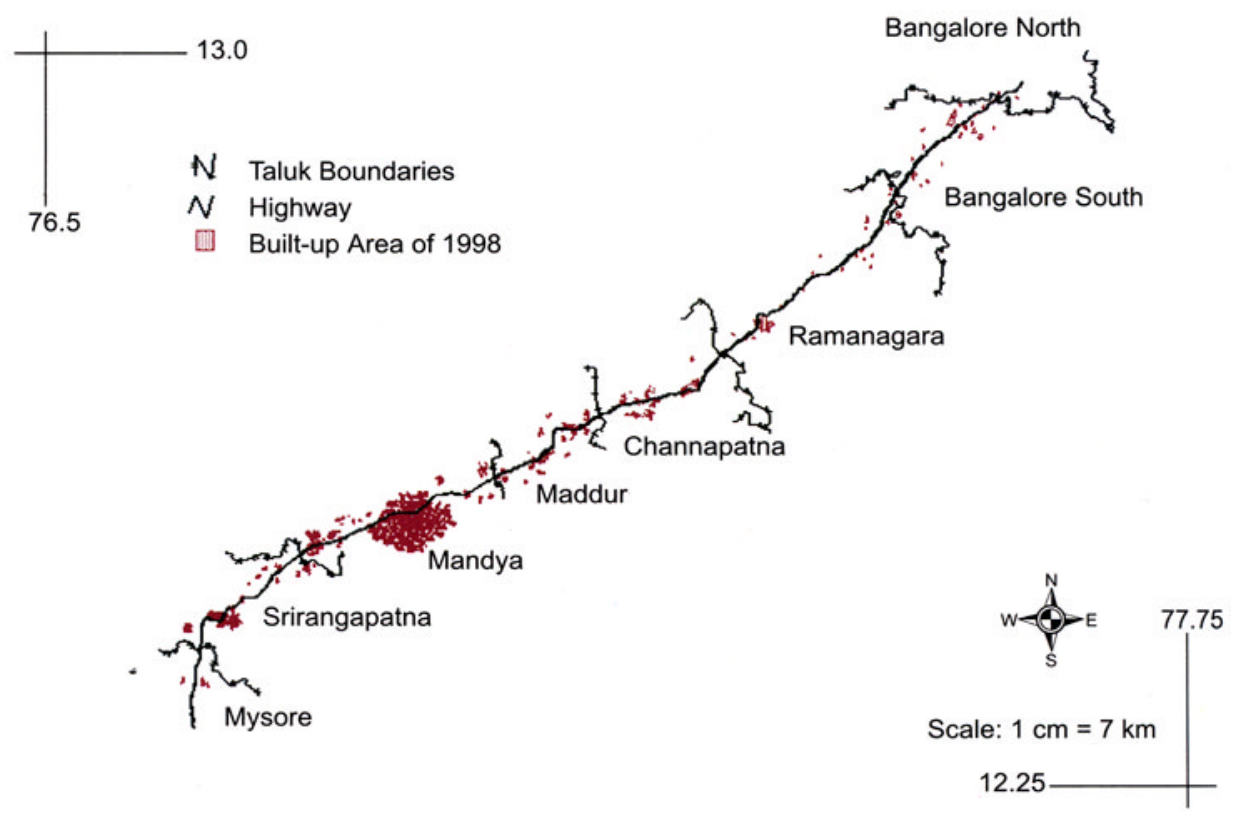

Fig. 4. Built-up Area in the Bangalore - Mysore Segment in 1998

From the classified image the area under the built-up theme was extracted and village-wise per cent built-up area was computed. This has been done by overlaying geo-referenced vector layer of taluks with village boundaries on a layer of built-up.

\section{Built-up Area and Shannon's Entropy}

The built-up area computed for temporal data indicated that there was $194 \%$ increase in the built-up area from the seventies to late nineties. A more detailed investigation of the distribution of the built-up (Table 2) revealed that the change is higher as the proximity to Bangalore increases. The Bangalore North - South segment had the highest increase in built-up area while it was least in Srirangapatna - Mysore segment with $128 \%$. It can also be observed that there is a declining trend in the change in built-up area as one travel from Bangalore to Mysore.
Shannon's entropy was computed for villagewise built-up area, wherein each village was considered as an individual zone $(\mathrm{n}=$ total number of villages). This revealed that the distribution of built-up area in the region in 1972 was slightly dispersed than in 1998. The values obtained ranges from 2.658 (in 1972) to 2.556 (in 1998) and $\log \mathrm{n}$ for this region is 4.477 . These are just over the half way mark of $\log \mathrm{n}$ (that is 2.238 ), which reveals some degree of dispersion. From the map of built-up area of 1998 (Fig. 4), by visual interpretation, it is seen that there is considerable increase in built-up area at Mandya. The calculation of entropy was for the entire stretch along the highway. This does not account for the considerable increase in the built-up area at Mandya. Hence in order to substantiate this, the entire study area along the highway was divided into segments and detailed investigations were done. 
Table 2. Built-Up Area and Shannon's Entropy for the Study Area

\begin{tabular}{|l|c|c|c|c|c|c|}
\hline \multirow{2}{*}{ Segment } & \multicolumn{2}{|c|}{$\begin{array}{c}\text { Built-up Area } \\
\left(\mathrm{km}^{2}\right)\end{array}$} & $\begin{array}{c}\text { Percentage } \\
\text { Change in } \\
\text { Built-up area }\end{array}$ & \multicolumn{2}{c|}{$\begin{array}{c}\text { Shannon's } \\
\text { Entropy }\end{array}$} & $\log _{\mathrm{e}} \mathrm{n}$ \\
\hline & $\mathbf{1 9 7 2}$ & $\mathbf{1 9 9 8}$ & & 1972 & $\mathbf{1 9 9 8}$ & \\
\hline Bangalore - Mysore & 8.2679 & 24.3344 & $194 \%$ & 2.658 & 2.556 & 4.477 \\
\hline Bangalore- Ramanagaram & 0.7494 & 3.2232 & $330 \%$ & 2.69 & 2.699 & 3.5835 \\
\hline Channapatna - Mysore & 7.5185 & 21.1112 & $181 \%$ & 2.320 & 2.083 & 3.9512 \\
\hline Bangaiore North - South & 0.1296 & 0.8538 & $559 \%$ & 2.427 & 2.338 & 2.565 \\
\hline Ramanagaram - Channapatna & 0.9682 & 3.2777 & $239 \%$ & 2.717 & 2.592 & 3.401 \\
\hline Mandya - Maddur & 5.9324 & 17.3804 & $193 \%$ & 1.662 & 1.434 & 3.434 \\
\hline Srirangapatna - Mysore & 1.2377 & 2.8226 & $128 \%$ & 1.803 & 1.922 & 2.639 \\
\hline
\end{tabular}

The segments were made based on the taluk boundaries intercepting within the buffer region, along the highway (Fig. 2). The entire segment of Bangalore - Mysore was split into two as Bangalore - Ramanagaram (comprising of taluks: Bangalore North, Bangalore South, and Ramanagaram) and Channapatna - Mysore segments (comprising of taluks: Channapatna, Maddur, Mandya, Srirangapatna and Mysore). The percentage built-up change and entropy was calculated for these two segments. The Bangalore - Ramanagaram segment had a higher value of percentage built-up change $(330 \%)$ than the Channapatna - Mysore segment (181\%). The entropy values for the Bangalore - Ramanagaram segment ranges from 2.690 (for 1972) to 2.699 (for 1998 ) while $\log n$ for this region is 3.583 suggests similar trend. In the Channapatna - Mysore segment the entropy value ranged from 2.320 (for 1972) to 2.083 (for 1998) and $\log n$ is 3.951 . This analysis reveals that the distribution is more dispersed in Bangalore - Ramanagaram segment compared to the latter.

To identify the location of actual sprawl, this region is further divided into four segments as Bangalore North - South, Ramanagaram Channapatna, Maddur - Mandya and
Srirangapatna - Mysore. From these results (Table 2), it is clear that there was more dispersed distribution of built-up area in the region closer to Bangalore and this decreased as the proximity to the city increased. The Bangalore North -South taluks had the highest increase in terms of the percentage built-up change and the entropy values also showed that there was more dispersion in this taluk, thus indicating higher sprawl in this region. Higher sprawl due to the proximity of Bangalore is observed till Channapatna - Ramanagaram segment. Also, it can be inferred that in the Mandya - Maddur segment the distribution was compact with radial sprawl and a considerable increase (193\%) in builtup area. However, in the Srirangapatna - Mysore segment the value of entropy showed marginal change and $128 \%$ increase in built-up. Here, the degree of sprawl is not as severe as that in case of other segments, but the marginal increase in entropy value certainly indicates the possibility of increasing sprawl due to enhanced economic activities at Mysore. Thus it is seen that all along the highway apart from Mandya, the linear sprawl along the highway has occurred. Mandya being the only district headquarters along the highway with intense economic activities exhibits radial 
growth. The usefulness of Shannon's entropy computation is evident from the fact that even though there was considerable increase in builtup area at segments like Bangalore North - South, Ramanagaram - Channapatna, Mandya - Maddur, the entropy purely reflected whether there is a compact growth or a dispersed growth.

\section{Conclusion}

The study investigated the urban sprawl phenomenon occurring along the Bangalore Mysore highway and found that there has been an overall increase in the built-up area by $194 \%$. The Bangalore North - South taluks having the highest percentage $(559 \%)$ increase and Srirangapatna - Mysore with the lowest percentage ( $128 \%$ ) change in built-up area. Further it was also found the change in built-up was high in the localities proximate to Bangalore. With the Shannon's entropy analysis, the study could identify where the sprawl was taking place and its degree as well. The Bangalore North - South taluks showed higher value entropy indicating sprawl, while the Mandya - Maddur taluks showed lower entropy value indicating compactness or less dispersion. Mandya being the only district headquarters along the highway, exhibited radial and compact growth. The usefulness of Shannon's entropy computation is that even though there was considerable increase in built-up area at segments like Bangalore North - South, Ramanagaram - Channapatna, Mandya - Maddur, the entropy merely reflected whether there is a compact growth or a dispersed growth. The study demonstrates that GIS and remote sensing coupled with statistical analysis, such as Shannon's entropy can help immensely in spatial and temporal analyses of the sprawl.

\section{Acknowledgements}

We thank Indian Space Research Organisation - Indian Institute of Science (ISRO - IISc) Space Technology Cell for financial assistance to carry out field investigations and National Remote Sensing Agency (NRSA),
Hyderabad for providing the satellite data required for the study. We are grateful to Ministry of Environment and Forests, Government of India and Indian Institute of Science for infrastructure support. We thank Mr. Aswath and Mr. Kamal for their active participation in field data collection and in preparation of base layers. We thank anonymous referees for their critical review, comments and suggestions, which helped in improving the MS.

\section{References}

Barnes, K.B., Morgan III, J.M., Roberge, M.C. and Lowe, S. (2001). Sprawl development: Its patterns, consequences, and measurement. Towson University. http://chesapeake. towson. edu/landscape/ urbansprawl/ download/ Sprawl_white_paper.pdf

Batty, M., Xie, Y. and Sun, Z. (1999). The dynamics of urban sprawl. Working Paper Series, Paper 15, Centre for Advanced Spatial Analysis, University College London.

http://www.casa.ac.uk/working_papers/

Berry, B.J.L. (1990). Urbanisation. In: The Earth as Transformed by Human Action (Eds.: B. L. Turner II, W.C. Clark, R.W. Kates, J.F. Richards, J.T. Mathews and W.B. Meyer). Cambridge University Press, U.K., pp.103-119.

Census of Indià. (1971). District Census Handbook South Kanara District. Series -14, Mysore, Directorate of Census Operations.

Census of India. (1981). District Census Handbook Dakshin Kannada District. Series -9, Karnataka, Directorate of Census Operations.

Epstein, J., Payne, K. and Kramer, E. (2002). Techniques for mapping suburban spraw1. Photogrammetric Engineering and Remote Sensing, 63(9): 913-918.

Hurd, J.D., Wilson, E.H., Lammey, S.G. and Civeo, D.L. (2001). Characterization of forest fragmentation and urban sprawl using time sequential Landsat Imagery. Proc. ASPRS Annual Convention, St. Louis, MO. April 23-27, 2001. 
http://resac.uconn.edu/publications/tech_papers/ index.html

Lata, K.M., Sankar Rao, C.H., Krishna Prasad, V., Badrinath, K.V.S., Raghavaswamy. (2001). Measuring urban sprawl: a case study of Hyderabad. GISdevelopment, 5(12): 26-29.

NAUTILUS (2001). Characterization of Urban Sprawl. http://resac.uconn.edu/research/urban_sprawl/ index.htm

The Regionalist (1997). Debate on Theories of David Rusk. 2(3).

Sierra Club (1998). The Dark Side of the American Dream: The Costs and Consequences of Suburban Sprawl. http://www.sierraclub.org/sprawl/ report981

Sudhira, H.S., Ramachandra, T.V. and Jagadish, K.S. (2003). Urban sprawl pattern recognition and modeling using GIS. Proc. Map India - 2003, New Delhi. January $28-31,2003$.

Sutton, P., Roberts, D., Elvidge, C. and Meij, H. (1997). A comparison of night-time satellite imagery and population density for the continental United States. Photogrammetric Engineering and Remote Sensing, 63(11): 1303-1313.

Torrens, P.M. and Alberti, M. (2000). Measuring sprawl. Working Paper No. 27, Centre for Advanced Spatial Analysis, University College London. http://www.casa.ac.uk/working papers/

Welch, R. (1980). Monitoring urban population and energy utilization patterns from satellite data. Remote Sensing of Environment, 9: 1-9.

Yeh, A.G.O. and Xia Li (2001). Measurement and monitoring of urban sprawl in a rapidly growing region using entropy. Photogrammetric Engineering and Remote Sensing, 67(1): 83p. 
ANNEXURE

\section{Illustration for Calculating Shannon's Entropy}

In the calculation of Shannon's entropy, the zone is considered as a village. The method of computing the Shannon's entropy is illustrated here with respect to two different time periods. Consider three villages (zones) $\mathrm{A}, \mathrm{B}$, and $\mathrm{C}$ as shown in Figures A-1 and A-2. The smaller polygons refer to the built-up area in the respective village boundary.

\section{Time Period 1}

In village $A$ there are 4 units, in $B$ there are 9 units, and in $C$ there are 6 units (Figure A-1). From the calculations the entropy (Table A-1) is 1.0459, while the maximum value of $\ln (n)$, i.e., $\ln (3)=1.098$. It can be seen that the degree of distribution as evident from the schematic map is dispersed in the villages.

\section{Time Period 2}

In village $A$ there are 8 units, in $B$ there are 12 units, and in $C$ there are 10 units (Figure A-2). From the calculations the entropy (Table A-2) is 1.0851 , while the maximum value of $\ln (n)$, i.e., $\ln (3)$ $=1.098$. Now it can be seen that the degree of dispersion has increased which is closer to the upper limit of $\ln (\mathrm{n}), 1.098$. Thus indicating increase in dispersion or indicating sprawl.

The change in entropy for different time period gives the degree of dispersion change in the region. Thus the entropy calculation and results are interpreted as a measure of quantifying the degree of dispersion in a spatial extent.

Table A-1. Calculation of Shannon's Entropy for Time Period 1

\begin{tabular}{|l|c|c|c|c|}
\hline Village & Built-up Area (units) & $\mathbf{P i}$ & $\ln (\mathbf{P i})$ & $\mathbf{P i} * \ln (\mathbf{P i})$ \\
\hline $\mathrm{A}$ & 4 & $4 / 19=0.2105$ & -1.5582 & -0.3280 \\
\hline $\mathrm{B}$ & 9 & $9 / 19=0.4736$ & -0.7473 & -0.3539 \\
\hline $\mathrm{C}$ & 6 & $6 / 19=0.3159$ & -1.1523 & -0.3640 \\
\hline Total & 19 & & $\Sigma \mathrm{Pi}^{*} \ln (\mathrm{Pi})=$ & -1.0459 \\
\hline
\end{tabular}

$\mathrm{H}^{\prime}=1.0459$ for Time Period 1

Table A-2. Calculation of Shannon's Entropy for Time Period 2

\begin{tabular}{|l|c|c|c|c|}
\hline Village & Built-up Area (units) & $\mathbf{P i}$ & $\ln (\mathbf{P i})$ & $\mathbf{P i}^{*} \ln (\mathbf{P i})$ \\
\hline $\mathrm{A}$ & 8 & $8 / 30=0.2666$ & -1.3220 & -0.3524 \\
\hline $\mathrm{B}$ & 12 & $12 / 30=0.4000$ & -0.9163 & -0.3665 \\
\hline $\mathrm{C}$ & 10 & $10 / 30=0.3334$ & -1.0984 & -0.3662 \\
\hline Total & 30 & & $\Sigma \mathrm{Pi}^{*} \ln (\mathbf{P i})=$ & -1.0851 \\
\hline
\end{tabular}

Hence, $H^{\prime}=1.0851$ for Time Period 2 


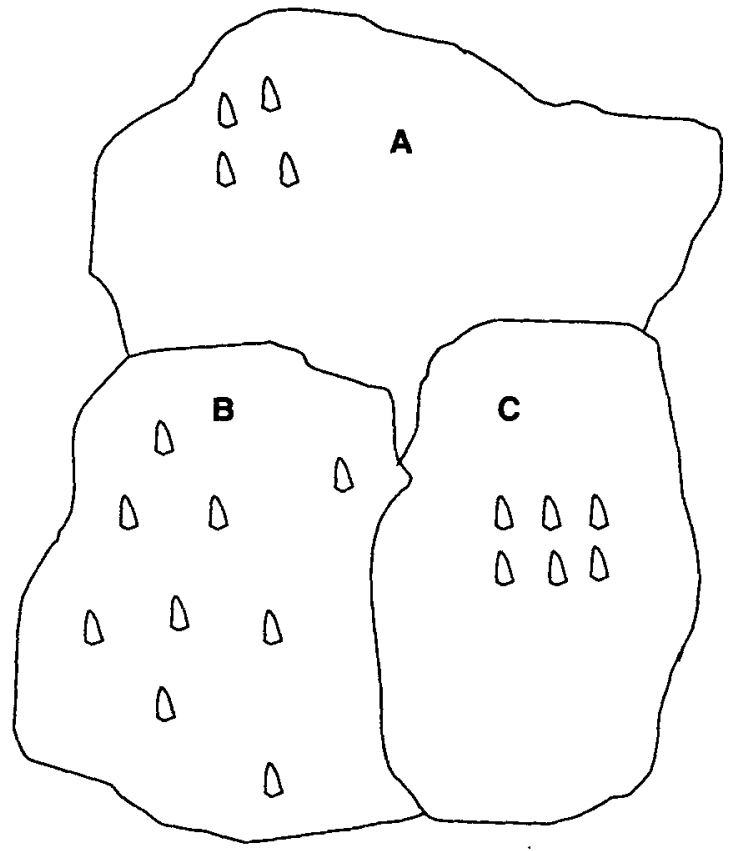

( Built-up Area

Fig. A-1. Built-up in Villages A, B, and C for Time Period 1

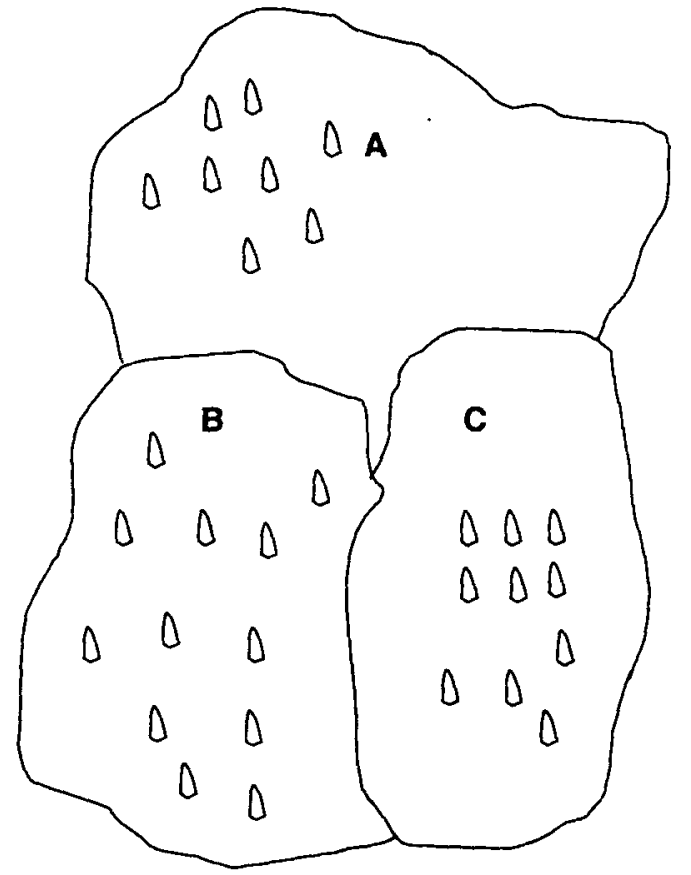

Built-up Area

Fig. A-2. Built-up in Villages A, B, and C for Time Period 2 